Hong JI

Yifan ZHOU

Qi LIU

\title{
OPTIMAL QUASI-PERIODIC PREVENTIVE MAINTENANCE POLICIES FOR A REPAIRABLE SYSTEM WITH STOCHASTIC MAINTENANCE INTERVAL
}

\section{OPTYMALNA STRATEGIA QUASI-OKRESOWEJ KONSERWACJI ZAPOBIEGAWCZEJ SYSTEMU NAPRAWIALNEGO - CZAS MIĘDZY PRZEGLĄDAMI JAKO WIELKOŚĆ STOCHASTYCZNA}

\begin{abstract}
The usual preventive maintenance (PM) of a repairable system is done before failure at integer multiples of time T. In some real cases, PM cannot be performed as soon as a planned PM period is reached because of effects of some random factors, while it is usually done within an implemented period, and thus it makes the PM period become a stochastic interval. From this viewpoint, a quasi-periodic imperfect preventive maintenance policy is proposed in this paper, in which a repairable system experiences either a minor failure or catastrophic failure when a failure occurs, and the first (N-1) PM intervals is divided into a planned PM period and an implemented period. In the former, the system may be suffered an unplanned PM for removing a catastrophic failure and performing a PM, whereas in the latter, the system is preventively maintained following an occurrence of a catastrophic failure or a dynamic PM plan, whichever comes first. At the Nth PM interval, the system is replaced either when a catastrophic failure occurs or operational time reaches $T$, whichever comes first. An optimization of the proposed mode is introduced, the existence and the uniqueness of the optimal solution are presented, and a useful constraint of the implemented period is obtained. Finally, a real case study of PM on Chinese diesel locomotives is examined to illustrate the proposed maintenance policy.
\end{abstract}

Keywords: maintenance; quasi-periodic imperfect preventive maintenance policy; implemented period; stochastic preventive maintenance interval.

\begin{abstract}
Zazwyczaj przeglądy okresowe systemu naprawialnego wykonuje się przed wystąpieniem uszkodzenia, w określonych odstępach czasu stanowiacych całkowita wielokrotność czasu T. W warunkach rzeczywistych, jednak, nie zawsze można przeprowadzić przeglad w zaplanowanym terminie ze względu na działanie pewnych losowych czynników, natomiast zazwyczaj przeprowadza się go w dopuszczalnym okresie realizacji, w związk z czym przedział czasu między przeglądami okresowymi staje się wielkościa stochastyczna. Biorac powyższe pod uwage, w niniejszej pracy zaproponowano strategie quasi-okresowej konserwacji zapobiegawczej, która zakłada, że system naprawialny może ulec albo drobnemu uszkodzeniu albo uszkodzeniu katastroficznemu, a czas, do którego należy wykonać pierwszy przegląd okresowy (N-1) można podzielić na zaplanowany czas przeprowadzenia przegladu oraz dopuszczalny okres realizacji przeglądu. W pierwszym przypadku, może wystapić konieczność przeprowadzenia nieplanowanej konserwacji systemu mającej na celu usunięcie uszkodzenia katastroficznego, natomiast w drugim, konserwacje przeprowadza się po wystapieniu uszkodzenia katastroficznego lub zgodnie z dynamicznym harmonogramem przeglądów, zależnie od tego, która z sytuacji zaistnieje wcześniej. W N-tym terminie przegladu okresowego, dokonuje się wymiany systemu, albo wskutek wystapienia uszkodzenia katastroficznego albo gdy czas pracy systemu osiagnie wartość T, zależnie od tego, co nastapi wcześniej. W artykule przedstawiono optymalizacje proponowanego trybu działania, wykazano istnienie i jednoznaczność optymalnego rozwiązania oraz wyznaczono przydatne ograniczenie dopuszczalnego okresu realizacji. Na koniec, proponowana politykę konserwacji zapobiegawczej zilustrowano studium przypadku chińskich lokomotyw spalinowych.
\end{abstract}

Stowa kluczowe: konserwacja; strategia quasi-okresowej niepetnej konserwacji zapobiegawczej; dopuszczalny okres realizacji przeglądu; czas między przeglądami jako wielkość stochastyczna.

\section{Introduction}

Maintenance systems are responsible for keeping equipment and assets fit, safe to operate and suitably configured to perform their tasks, and thus maintenance has a major impact on delivery, quality and cost. The choice of a maintenance policy is an important step in the planning of maintenance activities. Preventive maintenance $(\mathrm{PM})$ is one of some major maintenance policies, and it is important in complex systems because it can reduce downtime and breakdown risk. Nonetheless, it is inescapable for almost all users that a PM plan may be influenced regularly by some random factors, such as operational condition, production task, tasks of repairmen, processing time of a job, roundtrip cycle of the transport equipment, and catastrophic failures of the system, etc, which may result in an advancing or postponing to the PM plan at random, and thus users generally adjust the PM actions to be implemented within an allowable time period whose length is determined by engineers' experience. Consequently, PM periods become a stochastic value but not a fixed value in reality. Herein, 
the allowable time period is termed as the implemented period of PM activity. For example, the PM period in some Chinese locomotives is $23000 \mathrm{~km} \sim 30000 \mathrm{~km}[3,16]$, and it is $12 \sim 18$ months in some Japanese planes [4]. i.e. the planned PM period of Chinese diesel locomotives is $23000 \mathrm{~km}$, and the length of the implemented period is $7000 \mathrm{~km}$ and PM actions are executed randomly within [23000 30000] km. It is similar to Japanese planes. This PM policy is termed as quasi-periodic PM policy in this paper. It is a reasonable and popular approach because users can flexibly arrange the PM action according to their actual requirements in a short term. The selection of the implemented period's length is often considered according to some various factors. Under this situation, a PM action thus can be regarded as a random event that is limited in the implemented period, and the actual PM interval of the system is likely to be longer than the planned period. Therefore, it is necessary to optimize and discuss the quasi-periodic PM policy of a repairable system. Meanwhile, a question should be considered that how the length of the implemented period influences the maintenance cost, which may be more useful for users to make a PM decision.

Most of the current research assumed that the usual PM of a repairable system is done before failure at integer multiples of a fixed period $[6,9,14]$. Some of them considered the influence of some random factors on preventive replacement. Sheu et al,[13] considered a generalized age-replacement policy with age dependent minimal repair and a random lead-time. Castro and Sanjuan [1] analyzed a maintenance policy for a repairable system with delay repairs. In that paper, if the system fails in $\left[0, T^{*}\right)$ then it is repaired, whereas if it fails in $\left(T^{*}, T\right)$ the repair is not performed, and the system is replaced when the non-repairable failures reached $N$ over $\left(T^{*}, T\right)$. Xu et al, [15] discussed an age-dependent replacement policy, in which the interarrival lifetimes of components are characterized as random fuzzy variables. Chen [5] considered an age replacement policy for a system, which continuously works for multiple jobs with random working times, and can undergo minimal repairs upon failures. The planned replacement is postponed at the first completion of the working time or when a job incurs some damage to the system within a planned time $T$. Nakawaga [6] introduced several random replacement policy including age replacement, periodic replacement and block replacement policy. It is clear that these papers only considered the effect of system's internal factors on the PR policy. Few of them considered the other model with stochastic PM period. Nakagawa et al,[8] presented two random inspection policies, where a system is checked at periodic or successive times and also at every completion of working times. Gao et al,[3] introduced a case study on the sequential PM of combined governors in diesel locomotives, in which a sequential PM activity is performed within an allowable period whose length is determined by the engineer's experience, while the number of the PM is given which may lighten the complexity of the model. Chang[2] proposed several preventive maintenance policies for an operating system that works for jobs at random times and is imperfectly maintained upon failure. In these researches, PM action is only changed by a single factor, e.g. working cycle of a job, while it should be simultaneously affected by some external and internal factors. Therefore, an optimization problem for the periodic PM policy considering various effects of random factors is more reasonable and interesting.

In this paper, a quasi-periodic PM policy for repairable system with stochastic PM interval is introduced, which is different with the general periodic PM policy because the determination of the PM policy simultaneously considers some external and internal random factors, and the PM period is a limited random value rather than a fixed value. In this policy, the first $\left(N^{-}-1\right)$ PM intervals are divided into a planned PM period and an implemented period. Suppose that the failure of the system either is a minor or is a catastrophic failure with stochastic probability, and the PM plan would be changed by some random factors, and thus actual PM activities are randomly performed considering the dynamic PM plan and the occurrence of the catastrophic failure of the system. The main characteristic of this model is that catastrophic failures of the system and dynamic PM plan are competing to cause a PM action with different PM cost. Then, an optimization of the proposed model policy is introduced, and the existence and uniqueness of the optimal solution are clearly presented as well. In addition, a constraint of the implemented period is obtained, which may be a most useful conclusion for a real situation.

The rest of the paper is arranged as follows: The model and its assumption are introduced in section 2; model formulation and maintenance optimization are presented and explored in section 3; some special cases are analyzed in section 4; a real case study is examined in section 5; and a brief summary is given in the last section.

For ease of reference, some notations are stated as follows:

$a_{i} \quad$ adjustment factor in hazard rate function after the $\left(i^{-}-1\right)$ th

$\operatorname{PM}\left(1=a_{1} \leq a_{2} \leq, \ldots, \leq a_{N}\right)$

$A_{i}(t) \quad s$-expected total minor repair cost occurred over $(0, t)$

between the $(i-1)$ th and the $i$ th PM

$C \quad$ mean cost rate of the system

$\mathrm{C}_{e} \quad$ extra cost caused by a catastrophic failure

$C_{p, i} \quad$ cost of the ith PM

$\mathrm{C}_{r} \quad$ cost of a replacement

$\mathrm{C}_{m} \quad$ cost of a minimal repair

$F_{p, i}(y) \quad$ cumulative distribution function of minor failures occurred in the ith PM interval

$F_{q, i}(y) \quad$ cumulative distribution function of catastrophic failures occurred in the ith PM interval

$h_{i}(t) \quad$ hazard rate function at time $t$ of the system subject to $(i-1)$ PM, $i=1,2, \ldots, N$

$N \quad$ threshold of PM number

NHPP non-homogeneous Poisson process

$p_{i} \quad$ the probability of a failure is a minor failure when the system fails in the ith PM interval

$q_{i} \quad$ the probability of a failure is a catastrophic failure when the system fails in the ith PM interval

$R \quad$ total maintenance cost over a renewal cycle

$T \quad$ length of a planned periodic PM interval

$W \quad$ length of an impended period of PM activities

$Y \quad$ length of a renewal interval

$Y_{s, i} \quad$ occurring time of a catastrophic failure occurred in the $i$ th PM

$Y_{s c} \quad$ dynamic PM schedule over $[T T+W]$

Z random variable

\section{Model and its assumptions}

In the proposed quasi-periodic imperfect PM policy, a scheduled PM plan and a dynamic PM plan are presented. The scheduled $\mathrm{PM}$ plan is a long-term planning and is predetermined without considering the provisional effects of some random factors. According to the scheduled plan, the system is preventively maintained at $k T$ $(k=1,2, \ldots, N-1)$, and replaced at $N T$. Nevertheless, the dynamic PM plan is a short-term planning considering effect of some provisional external factors. The first $(N-1)$ PM interval is divided into a planned PM period and an implemented period. The length of the planned PM period is made by the scheduled PM plan and it is a fixed value with length $T$, while the length $W$ of the implemented period is given by engineers' experience in which the dynamic PM plan is randomly distributed. Minor repairs, PMs and a replacement activity are considered jointly in the maintenance policy. A replacement cycle is defined as the time interval between the installation of the system and the first replacement or between two consecutive replacements. Under this framework, the replacement cycle constitutes a regenerative process. The following context is about the introduction of the maintenance process and model assumptions. 
Without loss generality, assume that lifetime distribution of the system follows a general distribution $F(t)$ with finite mean value $\mu<+\infty$ and a probability density function $f(t)$. The hazard rate function $h(t)=f(t) / \bar{F}(t)$ is a continuous, positive and $h(t) \rightarrow+\infty$ as $t \rightarrow+\infty$, which is $a_{i} h(t)$ just before the $i$ th PM and becomes $h_{i+1}(t)=a_{i+1} h(t)$ $(i=1,2, \ldots, N-1)$ right after the $i$ th PM, here $a_{i}$ is adjustment factor in hazard rate function after the $(i-1)$ th $\mathrm{PM}\left(1=a_{1} \leq a_{2} \leq \ldots \leq a_{N}\right)[11]$ and $t \in[0, T+W]$. The system experiences one of the two types failure: minor failure and catastrophic failure. A failure either is a minor failure with probability $p_{i}$ or is a catastrophic failure with probability $q_{i}$ ( $q_{i}=1-p_{i}, i$ is the PM cycle), where $0 \leq q_{i} \leq 1$ and $q_{i}$ is non-decrease in $i$. The system is replaced when the PM number reaches the threshold $N$. After a replacement, it can be restored to "as good as new" state, and the operational procedure is repeated.

According to the PM in real cases, such as PM for locomotives, the planned PM period for the locomotive is $T$, while it may be adjusted in $\left[T-w_{1}, T+w_{2}\right]$ by engineers considering transport task or a transport cycle, etc., where $w_{1}$ and $w_{2}$ are constant and we set $w_{1}+w_{2}=W$. i.e. the actual PM schedule may be ahead of the planned PM schedule or delayed in a certain range. For ease of research, herein assume that the scheduled operational time period with a length $T$ and the implemented period with a length $W$. Consequently, the actual PM schedule randomly distributed within $[T, T+W]$. Certainly, an occurrence of a catastrophic of the system bring an unplanned PM in $(0, T)$ is possible, which is also considered in this model and explained in the following maintenance process.

The maintenance process is shown in Fig.1, where the planned PM actions intend to be implemented at $k T(k=1,2, \ldots, N-1$, it is replaced when $k=N$ ), whereas the actual PM actions are executed at the time $t_{l}$, $t_{2}, \ldots, t_{N}$ for the effects of some random factors mention above. Subplot (a) shows that the first $i$ th PM actions is performed at $t_{i}$ following the dynamic PM plan, and the system is preventively maintained for a occurrence of the catastrophic failure at $t_{i+1}$ (marked as $Y_{s, i+1}$ ). In this PM activity, removing of the catastrophic failure and the execution of the $(i+1)$ PM to the system is jointly performed, and thus the PM cost is different with the first $i$ th PM. Subplot (b) and (c) display the two cases of the replacement at the Nth PM interval. The former shows that the replacement is caused by a catastrophic failure at $t_{N}$ (marked as $Y_{s, N}$ ), where $t_{N}-t_{N-1}<T$; the latter exhibits that the replacement is executed at $t_{N}$ for the operational time reached $T$, the replacement cost is also different with the former.

Although there are some random factors affecting the PM activities, they may be forecasted in the relative short implemented period in practice. Thus the system can be arranged to be preventively maintained during the implemented period. According to this fact, we assume that the dynamic PM plan in the implement period following the uniform distribution with a probability density function $1 / W$. The dynamic PM schedules are marked as $Y_{s c}$ in each implemented period

in Fig. 1, where $Y_{s c} \in(0, W)$.

Finally, four model assumptions are given following above maintenance process:

1) All failures can be instantly detected and repaired.

2) A minor repair $C_{m}$ is unrelated to the occurred failures and the severed time of the system. The cost of PM $C_{p, i}(i$ denotes the $i$ th $\mathrm{PM}, i=1,2, \ldots, N-1)$ is not relevant to the severed times of the system, but it relates to the number of PM and it is a constant sequence increasing in $i$. A catastrophic failure causes an additional cost $C_{e}$. The cost of a planned replacement is a constant $C_{r}$, and it is $C_{e}+C_{r}$ for an unplanned replacement $\left(C_{e}+C_{p, i}<C_{r}, C_{r}>C_{m}\right)$.

3) The system can be arranged to be completely preventively maintained in each implemented period.

4) All minor repair, PM and replacement time are negligible.

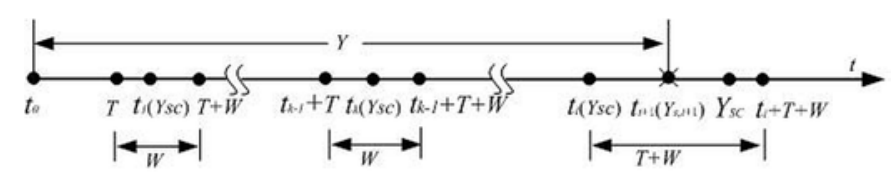

(a)

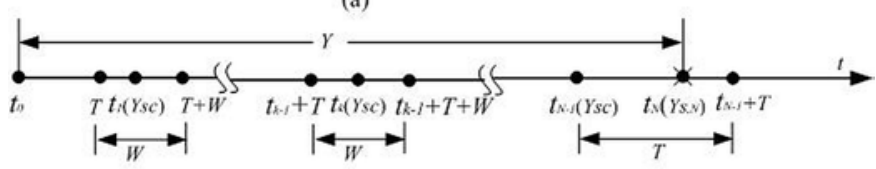

(b)

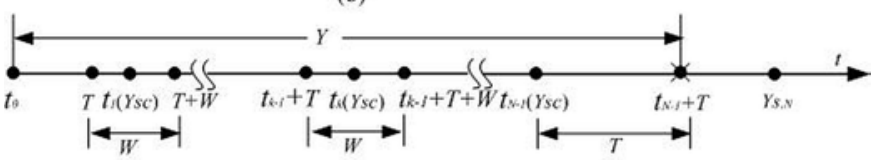

(c)

Fig. 1. Maintenance process plot

\section{Modeling and optimization}

According the above description of the maintenance process and model assumptions, modeling and optimization of the proposed quasiperiodic imperfect PM policy are presented in detail in this section.

\subsection{Modeling}

In terms of the model assumptions given in section 2, if no PM or replacement action is performed, the cumulative distribution function of minor failures between the $(i-1)$ th and $i$ th $(i=1,2, \ldots, N)$ PM can be written as:

$$
F_{p, i}(t)=1-\exp \left(-\int_{0}^{t} p_{i} h_{i}(y) \mathrm{d} y\right)
$$

Similarly, the cumulative distribution function of catastrophic failures between the $\left(i^{-1}\right)$ th and $i$ th $(i=1,2, \ldots, \mathrm{N})$ PM can be given by:

$$
F_{q, i}(t)=1-\exp \left(-\int_{0}^{t} q_{i} h_{i}(y) \mathrm{d} y\right)
$$

In order to describe the maintenance cost, a NHPP $\left\{N_{i}(t), t \geq 0\right\}$ become with intensity $h_{i}(t)$ and successive arrival time $X_{i, j}(i=1,2, \ldots, \mathrm{N})$ is considered. During each PM interval, a failure occurred at time $X_{i, j}$ $\left(X_{i, j} \in\left(t_{i}, t_{i+1}\right)\right)$ either is a minor failure with probability $p_{i}$ or is a catastrophic failure with probability $q_{i}$. Let $S_{i, j}$ is 1 or 0 , it is 1 if a failure is a minor failure, otherwise, it is 0 . Let $V_{i}(t)=\sum_{j=1}^{N_{i}(t)} S_{i, j}$ count the minor failure occurred in $(0, t)$ which is a $s$-independent NHPP with intensity $p_{i} h_{i}(t)$, and $N_{i}(t)-V_{i}(t)$ count the catastrophic failures occurred in $(0, t)$ which also is a $s$-independent NHPP with intensity $q_{i} h_{i}(t)$. Then, according to the Lemma 1 of the reference [12], if

$\left\{V_{i}(t), t>0\right\}$ beaNHPPwithintensity $p_{i}(t) h_{i}(t)$ and $E\left[V\left(t_{i}\right)\right]=\int_{0}^{t} p_{i} h_{i}(t) \mathrm{d} t$, and a $\operatorname{cost} C_{m}$ of a minor repair is occurred at the successive arrival time $X_{i, j}$, then the $s$-expected total minor repair cost occurred over $(0$, $t]$ between the $(i-1)$ th and the $i$ th PM can be expressed as below: 


$$
A_{i}(t)=C_{m} \int_{0}^{t} p_{i} h_{i}(u) \mathrm{d} u
$$

According to the introduction of maintenance process and model assumptions, there are six cases that may cause a PM or replacement in a renewal cycle, and thus the renewal cycle $Y$ of the system can be denoted as follows, where $Y_{s}, Y_{s c}$, which are presented as the definition in notations.

$$
\begin{gathered}
\left\{I_{Y_{\left(s_{i}\right)}<T}\left(Y_{s_{i}}\right)\right. \\
Y=\sum_{i=1}^{N-1}+I_{T<Y_{\left(s_{i}\right)}<T+Y_{(s c)}<T+W}\left(I_{S_{i}}\right) \\
\quad+I_{T+Y_{(s c)}<Y_{\left(s_{i}\right)}<T+W}\left(T+Y_{s c}\right)<+W<Y_{\left(s_{i}\right)} \\
\left.\quad\left(T+Y_{s c}\right)\right\}
\end{gathered}
$$

where $I_{B}(Z)$ is an indicator function of the set $B$, i.e.,

$$
I_{B}(Z)=\left\{\begin{array}{lc}
1, & \text { if } Z \in B \\
0, & \text { otherwise }
\end{array}\right.
$$

Similarly, the total maintenance cost of the renewal cycle is denoted as $R$, which can be described as below:

$$
\begin{gathered}
\left\{I_{Y_{\left(s_{i}\right)}<T, Y_{(s c)}<W}\left[A_{i}\left(Y_{s_{i}}\right)+C_{p, i}+C_{e}\right]\right. \\
R=\sum_{i=1}^{N-1}+I_{T<Y_{\left(s_{i}\right)}<T+Y_{(s c)}<T+W}\left[A_{i}\left(Y_{s_{i}}\right)+C_{p, i}+C_{e}\right] \\
+I_{(s c)}<Y_{\left(s_{i}\right)}<T+W \\
\left.+A_{i}\left(T+Y_{s c}\right)+C_{p, i}\right] \\
\left.+I_{Y_{\left(s_{N}\right)}<T}\left[A_{i}\left(Y_{s_{N}}\right)+C_{e}+C_{R}\right]+I_{T<Y_{\left(s_{N}\right)}}\left[A_{i}\left(T+Y_{s c}\right)+C_{p, i}\right]\right\}
\end{gathered}
$$

where $I_{B}(Z)$ is the same as above, other variables are defined as notations. The $s$-expected cost per unite time is stated as follows using the renewal reward theorem

$$
C(T)=\lim _{t \rightarrow+\infty} C(t) / t=E[R] / E[Y]
$$

where $E[R]$ and $E[Y]$ respectively denote the s-expected total maintenance cost and the $s$-expected renewal cycle, and thus they need to be computed firstly. $E[Y]$ can be given by:

$$
\begin{array}{cc}
\left\{\int_{0}^{T} y f_{q, i}(y) d y+\frac{1}{W}\left(\int_{0}^{W} \int_{T}^{T+u} y f_{q, i}(y) d y d u\right.\right. & \\
E[Y]=\sum_{i=1}^{N-1}+\int_{T}^{T+W} \int_{0}^{y-T}(T+u) f_{q, i}(y) \mathrm{d} u \mathrm{~d} y & +\int_{0}^{T} \bar{F}_{q, N}(y) \mathrm{d} y \\
+\int_{T+W}^{+\infty} & \left.\left.\int_{0}^{W}(T+u) f_{q, i}(y) \mathrm{d} u \mathrm{~d} y\right)\right\}
\end{array}
$$

which, upon simplification, is equal to:

$$
E[Y]=\frac{1}{W} \sum_{i=1}^{N-1}\left\{\int_{0}^{W} \int_{0}^{T+u} \bar{F}_{q, i}(y) \mathrm{d} y \mathrm{~d} u\right\}+\int_{0}^{T} \bar{F}_{q, N}(y) \mathrm{d} y
$$

Similarly, the $s$-excepted total cost of the renewal cycle can be stated as below:

$$
\begin{aligned}
E[R]=\frac{1}{W} \sum_{i=1}^{N-1}\left\{\int _ { 0 } ^ { T } \left[A_{0}^{W}\left[A_{i}(y)+C_{p, i}+C_{e}\right] f_{q, i}(y) \mathrm{d} u \mathrm{~d} y+\int_{0}^{W} \int_{T}^{T+u}\left[A_{i}(y)+C_{p, i}+C_{e}\right] f_{q, i}(y) \mathrm{d} y \mathrm{~d} u\right.\right. \\
\left.+\int_{0}^{T+W} \int_{T+u}^{T+u}\left[A_{i}(T+u)+C_{p, i}\right] f_{q, i}(y) \mathrm{d} y \mathrm{~d} u+\int_{0}^{W} \int_{T+W}^{+\infty}\left[A_{i}(T+u)+C_{p, i}\right] f_{q, i}(y) \mathrm{d} y \mathrm{~d} u\right\} \\
+\int_{0}^{T}\left(A_{N}(y)+C_{e}\right) f_{q, N}(y) \mathrm{d} y+A_{N}(T) \bar{F}_{q, N}(T)+C_{R}
\end{aligned}
$$

Let $M(T, N)$ denote the items that are relative to the minor repair cost $C_{m}$, and $J(T, N)$ denote the items that are relative to the extra cost $C_{e}$. They can be respectively interpreted as below:

$$
\begin{aligned}
M(T, N)= & \frac{1}{C_{m}}\left\{\frac { 1 } { W } \sum _ { i = 1 } ^ { N - 1 } \left\{\iint_{0}^{T} \int_{0}^{W} A_{i}(y) f_{q, i}(y) \mathrm{d} u \mathrm{~d} y+\int_{0}^{W} \int_{T}^{T+W} \int_{T}^{T+u} A_{i}(T+u) f_{q, i}(y) \mathrm{d} y \mathrm{~d} u+\int_{0}^{W} \int_{T+W}^{+\infty} A_{i, i}(y) \mathrm{d} y \mathrm{~d} u\right.\right. \\
& \left.+\int_{0}^{T} A_{N}(y) f_{q, N}(y) \mathrm{d} y+A_{N}(T) \bar{F}_{q, i}(y) \mathrm{d} y \mathrm{~d} u\right\} \\
J(T, N) & =\frac{1}{W} \sum_{i=1}^{N-1}\left\{\int_{0}^{T+W} F_{q, i}(y) \mathrm{d} y+\int_{T}^{T+W} F_{q, i}(y) \mathrm{d} y\right\}+F_{q, N}(T)
\end{aligned}
$$

which can simplified into:

$$
\begin{gathered}
M(T, N)=\frac{1}{W} \sum_{i=1}^{N-1}\left\{\frac{p_{i}}{q_{i}} \int_{T}^{T+W} F_{q, i}(y) \mathrm{d} y\right\}+\frac{p_{N}}{q_{N}} F_{q, N}(T) \\
J(T, N)=\frac{1}{W} \sum_{i=1}^{N-1} \int_{T}^{T+\mathrm{W}} F_{q, i}(y) \mathrm{d} y+F_{q, N}(T)
\end{gathered}
$$

Further, the s-excepted total cost is rewritten as:

$$
E[R]=\sum_{i=1}^{N-1} C_{p, i}+C_{R}+C_{m} M(T, N)+C_{e} J(T, N)
$$

Then, the $s$-expected cost per unite time can be given by Eq.(6).

$$
C(T, N)=\frac{\mathrm{E}[R]}{E[Y]}=\frac{\sum_{i=1}^{N-1} C_{p, i}+C_{m} M(T, N)+C_{e} J(T, N)+C_{R}}{\frac{1}{W} \sum_{i=1}^{N-1}\left\{\int_{T}^{T+W} \int_{0}^{T} \bar{F}_{q, i}(y) \mathrm{d} y \mathrm{~d} u\right\}+\int_{0}^{T} \bar{F}_{q, N}(y) \mathrm{d} y}
$$

In the following parts, an optimal $N^{*}$ and optimal $T^{*}$ need to be find which together minimize $C(T, N)$ in the infinite-horizon case.

\subsection{Optimal value of $\mathrm{T}^{*}$}

The focus of this subsection is to find the optimal value $T^{*}$ that can minimize the function $C(T ; N)$ given in Eq.(6). Firstly, differentiating $C(N, T)$ in Eq.(6) with respect to $T$ and setting $d C / d T=0$ yields:

$$
\begin{aligned}
C\left(T^{*} ; N\right) & =\frac{C_{m} M^{\prime}\left(T^{*}, N\right)+C_{e} J^{\prime}\left(T^{*}, N\right)}{E[Y]^{\prime}} \\
= & \frac{\sum_{i=1}^{N-1}\left(C_{m} \frac{p_{i}}{q_{i}}+C_{e}\right) \int_{T^{*}}^{T^{*}+W} f_{q, i}(u) \mathrm{d} u+W\left(C_{m} \frac{p_{N}}{q_{N}}+C_{e}\right) f_{q, N}\left(T^{*}\right)}{\sum_{i=1}^{N-1} \int_{T^{*}}^{T^{*}+W} \bar{F}_{q, i}(u) \mathrm{d} u+W \bar{F}_{q, N}\left(T^{*}\right)}
\end{aligned}
$$


Then, submitting Eq.(6) into Eq.(7) implies Eq.(8)

$$
\begin{aligned}
& \sum_{i=1}^{N-1} C_{p, i}+C_{R}=E[Y] \frac{C_{m} M^{\prime}(T, N)+C_{e} J^{\prime}(T, N)}{E[Y]^{\prime}}-C_{m} M(T, N)-C_{e} J(T, N) \\
& =\frac{\left\{\sum_{i=1}^{N-1}\left(C_{m} \frac{p_{i}}{q_{i}}+C_{e}\right) \int_{T}^{T+W} f_{q, i}(u) \mathrm{d} u+\left(C_{m} \frac{p_{N}}{q_{N}}+C_{e}\right) W f_{q, N}(T)\right\}\left\{\frac{1}{W} \sum_{i=1}^{N-1} \int_{T}^{T+W} \int_{0}^{u} \bar{F}_{q, i}(y) \mathrm{d} y \mathrm{~d} u+W \int_{0}^{T} \bar{F}_{q, N}(y) \mathrm{d} y\right\}}{\sum_{i=1}^{N-1} \int_{T}^{T+W} \bar{F}_{q, i}(u) \mathrm{d} u+W \bar{F}_{q, N}(T)} \\
& -\left\{\frac{1}{W} \sum_{i=1}^{N-1}\left(C_{m} \frac{p_{i}}{q_{i}}+C_{e}\right) \int_{T}^{T+W} F_{q, i}(y) \mathrm{d} y+\left(C_{m} \frac{p_{N}}{q_{N}}+C_{e}\right) F_{q, N}(T)\right\}
\end{aligned}
$$

The solution of Eq.(8) is optimal $T^{*}$ if it is existent. To prove its (i.e., $T^{*}, \min (C(N ; T))=C\left(T^{*} ; N\right)$ ) existent and uniqueness under certain conditions, the effect of $W$ in Eq.(8) needs to be determined firstly. To this end, set the right hand side (rhs) of Eq.(8) to be $\phi(T ; N)$.

$$
\begin{aligned}
& \phi(T ; N)=\frac{\left\{\sum_{i=1}^{N-1}\left(C_{m} \frac{p_{i}}{q_{i}}+C_{e}\right) \int_{T}^{T+W} f_{q, i}(u) \mathrm{d} u+\left(C_{m} \frac{p_{N}}{q_{N}}+C_{e}\right) W f_{q, N}(T)\right\}}{\sum_{i=1}^{N-1} \int_{T}^{T+W} \bar{F}_{q, i}(u) \mathrm{d} u+W \bar{F}_{q, N}(T)}\left\{\frac{1}{W} \sum_{i=1}^{N-1} \int_{T}^{T+W} \int_{0}^{u} \bar{F}_{q, i}(y) \mathrm{d} y \mathrm{~d} u+W \int_{0}^{T} \bar{F}_{q, N}(y) \mathrm{d} y\right\} \\
& -\left\{\frac{1}{W} \sum_{i=1}^{N-1}\left(C_{m} \frac{p_{i}}{q_{i}}+C_{e}\right) \int_{T}^{T+W} F_{q, i}(y) \mathrm{d} y+\left(C_{m} \frac{p_{N}}{q_{N}}+C_{e}\right) W F_{q, N}(T)\right\}
\end{aligned}
$$

Further, let

$$
\varepsilon(T ; N)=\frac{\left\{\sum_{i=1}^{N-1}\left(C_{m} \frac{p_{i}}{q_{i}}+C_{e}\right) \int_{T}^{T+W} f_{q, i}(u) \mathrm{d} u+\left(C_{m} \frac{p_{N}}{q_{N}}+C_{e}\right) W f_{q, N}(T)\right\}}{\sum_{i=1}^{N-1} \int_{T}^{T+W} \bar{F}_{q, i}(u) \mathrm{d} u+W \bar{F}_{q, N}(T)}
$$

and

$$
\vartheta=\lim _{T \rightarrow+\infty} \frac{\sum_{i=1}^{N-1} C_{p, i}+C_{m} M(T, N)+C_{e} J(T, N)+C_{R}}{\frac{1}{W} \sum_{i=1}^{N-1}\left\{\int_{T}^{T+W} \int_{0}^{T} \bar{F}_{q, i}(y) \mathrm{d} y \mathrm{~d} u\right\}+\int_{0}^{T} \bar{F}_{q, N}(y) \mathrm{d} y}
$$

According to actual case, generally $T>W$, and thus let $T=W$ in Eq.(9). Then we have $\phi(W ; N)$ as the function with regard to $W$ :

$$
\phi(W ; N)=\left.\phi(T ; N)\right|_{T=W}
$$

Finally, setting the left hand side (lhs) of Eq.(8) to be $\phi\left(w_{P, N} ; N\right)$ yields Eq.(11), where $w_{P, N}>0$ is a solution to Eq.(11).

$$
\sum_{i=1}^{N-1} C_{p, i}+C_{R}=\phi\left(w_{P} ; N\right)
$$

The proof of the solution to Eq.(11) is existent and unique using the following theorem 1.

Theorem 1 Assume that $h(t)$ is an increasing or "bathtub" type function, and $h(t) \rightarrow+\infty$ as $t \rightarrow+\infty$, and $a_{i} h(t)<a_{i+1} h(t)$, then the solution of $w_{P}>0$ to Eq.(11) is existent and unique if $\varepsilon(+\infty ; N)>\vartheta$.
The proof of the theorem is shown in appendix $A$.

Furthermore, in terms of Theorem 1 and the following theorem, the solution to Eq.(8) is existent and unique as well.

Theorem 2 Assume that $h(t)$ is an increasing or "bathtub" type function, $h(t) \rightarrow+\infty$ as $t \rightarrow+\infty$, and $a_{i} h(t)<a_{i+1} h(t)$, then the solution of $T>W$ to Eq.(8) is existent and unique if $\varepsilon(+\infty ; N)>\vartheta$ and the given $W \in\left(0, w_{P}\right]$.

The proof of this theorem is similar as the theorem 1 .

According to above theorem, $w_{P}$ is the constraint of experience value $W$. Till then, for a system, $C_{m}, p_{i}$ and $h(t)$ are known, and under an identical maintenance condition, $a_{i}$ is also known. Thus, the optimal solution $T \geq W$ is existent if $W \leq w_{P}$, otherwise, the experience value $W$ is too large for the case.

\subsection{Optimal value of $N^{*}$}

According, the following in-equation holds for the optimal value of $N$ if $N>1$ :

$$
C(T, N+1) \geq C(T, N)
$$

$$
\text { and } C(T, N-1) \geq C(T, N)
$$

According to $C(T, N+1) \geq C(T, N)$ and $C(T, N-1) \geq C(T, N)$, in-equations $S(T, N) \geq C_{R}$ and $S(T, N-1)<C_{R}$ can be obtained respectively, where:

$$
\begin{aligned}
S(T, N)= & \frac{C_{p, N-1}+C_{m}(M(T, N+1)-M(T, N))+C_{e}(J(T, N+1)-J(T, N))}{\frac{1}{W} \int_{T}^{T+W} u} \int_{0}^{T} \bar{F}_{q, N}(y) \mathrm{d} y \mathrm{~d} u+\int_{0}^{T}\left(\bar{F}_{q, N+1}(y)-\bar{F}_{q, N}(y)\right) \mathrm{d} y \\
& \left\{\frac{1}{W} \sum_{i=1}^{N-1}\left\{\int_{T}^{T+W} \int_{0}^{u} \bar{F}_{q, i}(y) \mathrm{d} y \mathrm{~d} u\right\}+\int_{0}^{T} \bar{F}_{q, N}(y) \mathrm{d} y\right\}-\left\{\sum_{i=1}^{N-1} C_{p, i}+C_{m} M(T, N)+C_{e} J(T, N)\right\}
\end{aligned}
$$


$S(T, N)$ keeps increasing in $N$ for all $T>0$, as can be observed in the following:

$$
\begin{aligned}
S(T, N)-S(T, N-1)= & \left\{\frac{C_{p, N}+C_{m}(M(T, N+1)-M(T, N))+C_{e}(J(T, N+1)-J(T, N))}{T}\right. \\
& \int_{0}^{T} \int_{T}^{T+u} \bar{F}_{q, N}(y) \mathrm{d} y \mathrm{~d} u+\int_{0}^{T}\left(\bar{F}_{q, N+1}(y)-\bar{F}_{q, N}(y)\right) \mathrm{d} y \\
& \left.-\frac{C_{p, N-1}+C_{m}(M(T, N)-M(T, N-1))+C_{e}(J(T, N)-J(T, N-1))}{T}\right\} \\
& \int_{0}^{T+u} \int_{T}^{T+u} \bar{F}_{q, N-1}(y) \mathrm{d} y \mathrm{~d} u+\int_{0}^{T}\left(\bar{F}_{q, N}(y)-\bar{F}_{q, N-1}(y)\right) \mathrm{d} y \\
& {\left[\sum_{i=1}^{N-1}\left\{\int_{0}^{W} \int_{0}^{T+u} \bar{F}_{q, i}(y) \mathrm{d} y \mathrm{~d} u\right\}+W \int_{0}^{T} \bar{F}_{q, N}(y) \mathrm{d} y\right]>0 }
\end{aligned}
$$

It is thus verified that an unique $N$ can be determined by $S(T, N) \geq C_{R}$ and $S(T, N-1)<C_{R}$ and an unique $N^{*}$ does exist for minimizing the mean cost per unit time $C(T, N)$.

\section{Special cases}

This section displays some especial cases of the proposed model.

$$
\text { Case } 1 \quad W=0 \text { and } p_{i}=1, C_{p, i}=C_{p}
$$

This model is the periodic imperfect PM policy [7], in which the system is preventively maintained at $k T(k=1,2, \ldots, N-1)$ and is replaced at $N T$, and failures are removed by minor repair. Following is the mean cost rate function.

$$
C(T ; N)=\frac{\mathrm{E}[R]}{E[Y]}=\frac{(N-1) C_{p}+C_{m} \sum_{i=1}^{N} \int_{0}^{T} h_{i}(y) \mathrm{d} y+C_{R}}{N T}
$$

\section{Case $2 \quad W=0$ and $p_{i} \neq 1$}

This model is the periodic imperfect PM policy, in which the system is planned to be preventively maintained at $k T(k=1,2, \ldots, N-1)$ and is replaced at $N T$. The system experiences one of the two types failure: minor failure and catastrophic failure. Minors are removed by minor repair, whereas catastrophic failures are recited by a unplanned PM with cost $C_{e}+C_{p, i}\left(\right.$ or $\left.C_{e}+C_{r}, k=N\right)$.

$$
C(T ; N)=\frac{\mathrm{E}[R]}{E[Y]}=\frac{\sum_{i=1}^{N-1} C_{p, i}+\sum_{i=1}^{N}\left(C_{\mathrm{e}}+\frac{p_{i}}{q_{i}} C_{m}\right) F_{q, i}(T)+C_{R}}{\sum_{i=1}^{N} \int_{0}^{T} \bar{F}_{q, i}(y) \mathrm{d} y}
$$

According to the mean cost rate of the special case 2 is given as Eq.(17). The optimal $T^{*}$ of the periodic PM policy can be obtained from Eq.(18), and the optimal $N^{*}$ can be attained from the in-equation (19) under the Matlab2010.

$$
C_{R}+\sum_{i=1}^{N-1} C_{p, i}=\frac{\sum_{i=1}^{N} \int_{0}^{T} \bar{F}_{q, i}(y) \mathrm{d} y}{\sum_{i=1}^{N} \bar{F}_{q, i}(T)} \sum_{i=1}^{N}\left(C_{\mathrm{e}}+\frac{p_{i}}{q_{i}} C_{m}\right) f_{q, i}(T)-\sum_{i=1}^{N}\left(C_{\mathrm{e}}+\frac{p_{i}}{q_{i}} C_{m}\right) F_{q, i}(T)
$$

$$
L(N-1 ; T) \leq C_{r} \leq L(N ; T)
$$

$L(N ; T)=\frac{C_{p, N}+\left(C_{\mathrm{e}}+\frac{p_{N+1}}{q_{N}} C_{m}\right) F_{q, N}(T)}{\int_{0}^{T} \bar{F}_{q, N+1}(y) \mathrm{d} y} \sum_{i=1}^{N} \int_{0}^{T} \bar{F}_{q, i}(y) \mathrm{d} y-\left\{\sum_{i=1}^{N-1} C_{p, i}+\sum_{i=1}^{N}\left(C_{\mathrm{e}}+\frac{p_{i}}{q_{i}} C_{m}\right) F_{q, i}(T)\right\}$

\section{Case $3 \quad W \neq 0$ and $p_{i}=1$}

This model is a quasi-periodic imperfect PM policy, in which the system is replaced after $(N-1)$ PM actions, and each PM plan is randomly distributed in $(T, T+W]$ with probability density $1 / W$, and failures are removed by minor repair. The mean cost rate function is stated as follows:

$C(T ; N)=\frac{\mathrm{E}[R]}{E[Y]}=\frac{W C_{R}+\sum_{i=1}^{N-1}\left(W C_{p, i}+C_{m} \int_{T}^{T+W} \int_{0}^{u} h_{i}(y) \mathrm{d} y \mathrm{~d} u\right)+C_{m} W \int_{0}^{T} h_{i}(y) \mathrm{d} y}{N T+(N-1) 0.5 W}$

\section{Real cases study}

In this section, the procedures and features of the proposed model and some sensitive analysis on model parameters are illustrated using a real case study on one type of Chinese diesel locomotive. Diesel locomotives are intensively used in most Chinese railway enterprises, and their maintenance becomes a hot issue in daily operating. Periodic PM is widely used for the convenience of scheduling, and an overhaul is performed after 4 6 PMs in current [16]. Meanwhile, the PM plan usually includes a scheduled PM plan and a dynamic PM plan, and actual PM action is dynamic and stochastic in maintenance period for the influence of production trust, tasks of repairmen, condition of the whole locomotive, etc. The planned PM period $T$ of some Chinese diesel locomotives is $23000 \mathrm{~km}$, and the implemented period $W$ is $7000 \mathrm{~km}$, and thus PM actions are executed randomly within [23000 30000]. Therefore, PM of diesel locomotives satisfies the characteristic of the proposed dynamic quasi-periodic PM, and thus their maintenance is used as a real case study to illustrate the proposed PM policy.

\subsection{Maintenance optimization}

Herein, we assume that the maintenance cost modeling satisfies the following assumptions:

1) The dynamic PM plan is randomly distributed following the uniform distribution with a probability density function $1 / W$ within $\left[T^{*} T^{*}+W\right]$.

2) The overhaul is the same as replacement and can restore the system to "as good as new".

3) $\quad p_{i}$ and $a_{i}$ are the sequence of $i$ :

$$
\begin{aligned}
& p_{i}=\gamma^{i^{\theta}}-\gamma^{(i+1)^{\theta}}+\gamma \\
& a_{i}=0.85+0.15 i
\end{aligned}
$$

4) Other assumptions are the same as the quasi-periodic PM policy in part 2.

Other parameters are shown as following Table 1.

The reliability model of the diesel locomotive in summer is obtained from maintenance recorders [16], and its hazard rate function is given as bellows:

$$
h(t)=\frac{f(t)}{\bar{F}(t)}=2.49 \times 10^{-5}(t / 35199)^{-0.1246}+1.73 \times 10^{-4}(t / 34289)^{4.9318}
$$

Where: 
Table 1. Parameters

\begin{tabular}{cclccl}
\hline Items & Value & Remarks & Items & Value & \multicolumn{1}{c}{ Remarks } \\
\hline$C_{r}$ & $10000 Y$ & Assume & $W$ & $7000 \mathrm{~km}$ & $\begin{array}{l}\text { A current maintenance regulation of } \\
\text { one type Chinese diesel locomotives }\end{array}$ \\
$C_{e}$ & $6000 Y$ & Assume & $\gamma$ & 0.85 & Assume \\
$C_{m}$ & $5000 Y$ & Assume & $\theta$ & 0.75 & Assume \\
$C_{p, i}$ & $2000 Y$ & Assume & & & \\
\hline
\end{tabular}

It can be found that $h(t)$ is a "bathtub" type function, which is discussed above. Then, for convenience of getting the solution, an algorithm following the analysis is given, which can be used to compute numerically the optimal number $N^{*}$, and the optimal period $T^{*}$.

Algorithm

Step1 Input parameters $\gamma, \theta, C_{m}, C_{e}, C_{p, i}, C_{r}, a_{i}, W$ and set $N=1$.

Step2 Substitute $N$ into Eq.(11), we can obtain $W_{P}$. If $W \leq w_{p}$, then go to the next step.

Otherwise, the solution is inexistence and the algorithm ends.

Step3 Substitute $N$ into Eq.(8), and $T$ ' is obtained, and go to the next step.

Step4 Substitute the obtained $T^{\prime}$ into $S\left(T^{\prime}, N\right)$, attained $N^{\prime}$. If $N^{\prime}=N$, go to the step6.

Otherwise, go to the next step.

Step 5 Set $N=N+1$, go to the step2.

Step6 Give outputs of the optimal $T^{*}=T^{\prime}$ and $N^{*}=N^{\prime}$, and the algorithm ends.

Under the Matlab 2010b, the optimal $N^{*}=5, T^{*}=21420 \mathrm{~km}$, the $C\left(T^{*}, N^{*}\right)=0.38826 Y / \mathrm{km}$ and $w_{P}=16450 \mathrm{~km}$ are obtained. i.e. for Chinese diesel locomotives in summer in the area, the optimal solution is existent and unique if the implemented period $W \leq 16450$, and dynamic PM activities are performed stochastically in time period [21420, $28420]$. The three-dimension of $(N, t, C)$ is shown as Fig. 2 , from which the existence of $C_{\min }$ can be found directly.

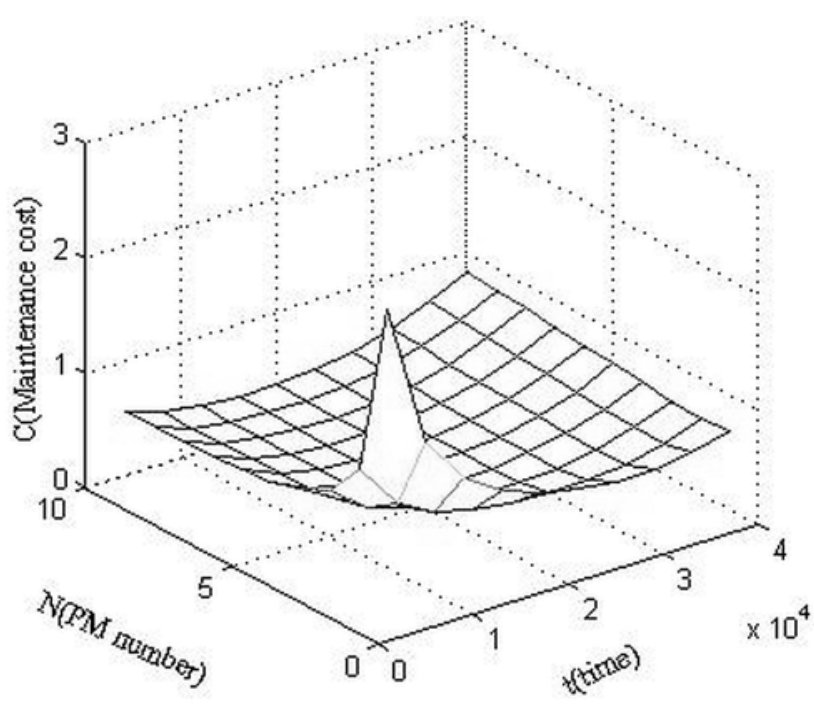

Fig. 2. Three-dimension plot of $(N, t, C)$

\subsection{Discussion}

a) Effect analysis of $W$

According to the proposed PM policy, $W$ is the only and critical parameter that can be determined by users, and thus it is necessary to analysis its influence on the optimal result. Subplot $(a)$ of Fig. 3 shows the trend of long running cost rate with the increase of $W$. It can be found directly that the growth of $W$ can increase the long running cost rate. Subplot $(b)$ of Fig. 3 exhibits the probable operating time zone of the system with the increase of $W$. It illustrates that the increase of $W$ can cause a decrease of $T$ and enlarge probable operating time zone. A long $W$ may be convenient for repairman, but maybe discommodity for production. Therefore, the choice of $W$ should be decreased as soon as possible under the condition of meeting the requirements of practice.

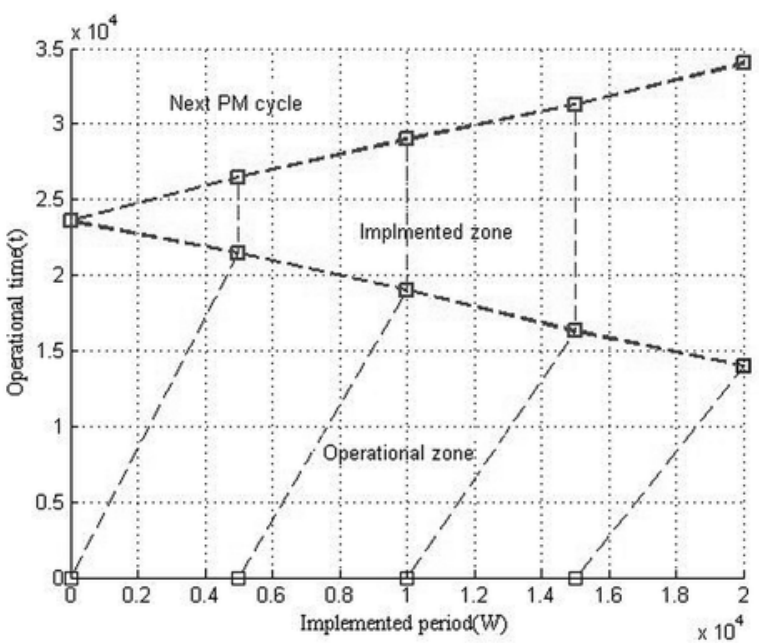

(a) Plot on $\mathrm{W}-C_{\min }$

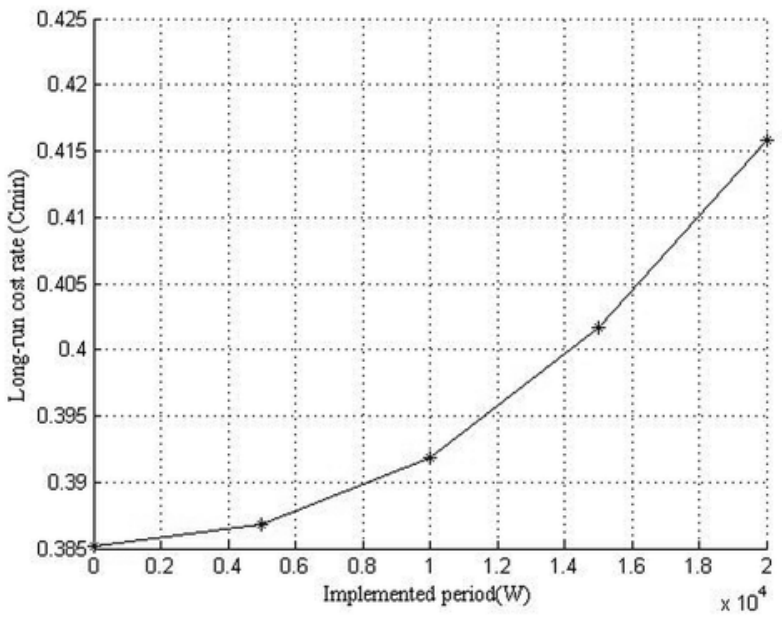

(b) Plot on $W-t$

Fig. 3. Optimal results with different $W$

b) Necessity analysis of the proposed policy

In reality, PM actions always stochastically performed in each implemented period $\left[T_{0}, T_{0}+W\right]$ if ignore the randomness of PM, where $T_{0}$ is the optimal PM cycle when $W=0$. It can be seen from Fig. 4 that the actual maintenance cost rate is greater than the policy without considering the implemented period $(W=0)$. Assume that the time of perform PM action is $T_{S}\left(T_{S} \in\left[T_{0}, T_{0}+W\right]\right)$, the actual maintenance cost rate is $C\left(T_{s}\right)$ that stochastically distribute within $\left[\max \left(C\left(T_{s}\right)\right), \min \left(C\left(T_{s}\right)\right)\right]$. 
Fig. 4 shows probable cost rate with different maintenance policy, illustrated with the following two cases.

Case 1: The PM cycle $T_{0}$ is determined by the usual PM policy $(W=0)$, while the actual PM is performed within $\left[T_{0}-w_{1}, T_{0}+w_{2}\right]$, where $W=w_{1}+w_{2}=7000$. It can be found that the actual cost rate stochastically distributes within $[0.388,0.402]$ and the mean value is nearly 0.396 , while the computed cost rate is 0.385 . That is to say, the computed cost rate is not the truth, and the waste must be occurred. Meanwhile, we can also found that the actual maintenance cost rate is increasing with the increase of $W$ (e.g. $W=8000$ ).

Case 2: The PM cycle is determined by the proposed PM policy with $W=7000$, where the mean cost rate is $0.388<0.396$. The save part is greater than the gap of the general PM and the general sequential PM policy. This result illustrates the necessity of the proposed PM policy.

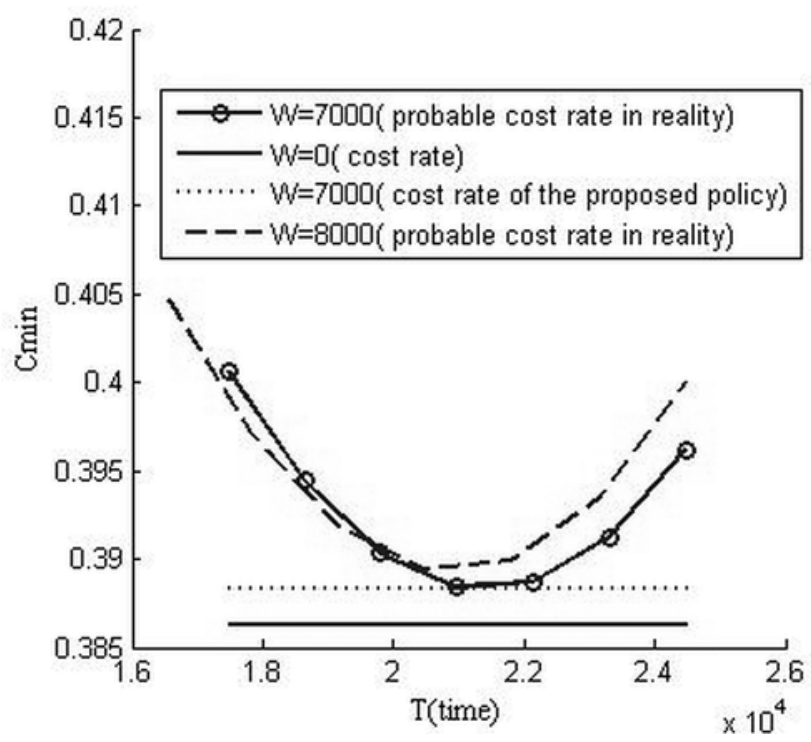

Fig. 4. Probable cost rate with different maintenance policy

\section{Results}

In this paper, a quasi-periodic imperfect PM policy for repairable system with stochastic maintenance interval was proposed. Expected long-run cost per unit time for the operating system was determined. The optimal PM number $N^{*}$ and optimal implemented period $\left[T^{*}\right.$, $\left.T^{*}+W\right]$ for PM actions were also derived, their existence and uniqueness being well demonstrated as well. The constraint of the experience value $W$ was also obtained in theory. Some special cases of the proposed model were discussed in brief, and a real case study on Chinese diesel locomotives was provided for verification. From the case study, effects of $W$ on optimal results and necessity of the proposed PM policy were discussed. In addition, it was found from the compare that the PM cost rate exist a great gap between considering and not considering the randomness of PM actions in PM policy making. It should be paid close attention in practice that the cost rate is increasing with the increase of $W$, and the length of $W$ should be small as far as possible under satisfying the needs of practice. The obtained results can be extended to further studies on the sequential PM with stochastic maintenance interval. We are currently working on some of these topics.

\section{Acknowledgements}

The authors are grateful for valuable suggestions of Guanjun Wang, an associate professor of the Department of Mathematics, Southeast University of China. The research work is also supported jointly by the Natural Science Foundation of China (51275090 and 71201025), and the opening topic fund of Jiangsu key laboratory of large engineering equipment detection and control (JSKLEDC201404).

\section{Appendix}

Theorem 1: Assume that $h(t)$ is an increasing or "bathtub" type function, and $h(t) \rightarrow+\infty$ as $t \rightarrow+\infty$, and $a_{i} h(t)<a_{i+1} h(t)$, then the solution of $w_{P}>0$ to Eq.(11) is existent and unique.

Proof:

1) If $h(t)$ is an increasing function and $h(t) \rightarrow+\infty$ as $t \rightarrow+\infty$, and $a_{i} h(t)<a_{i+1} h(t) . \phi(W)$ and $\varepsilon(W)$ are increasing in $W$ since $h(t)$ is strictly increasing in t. $\lim _{W \rightarrow 0} \phi(W)=0$, and $\vartheta \approx$ constant, and $\lim _{W \rightarrow+\infty} \phi(W)=+\infty$ and $\varepsilon(+\infty)>\vartheta$.

Then, $0<C_{r}<\phi(+\infty)$. The solution of $w_{P}>0$ to Eq.(11) is existent and unique.

The proof of the theorem can refer [10] in detail.

2) If $h(t)$ is a "bathtub" type function and $h(t) \rightarrow+\infty$ as $t \rightarrow+\infty$, and $a_{i} h(t)<a_{i+1} h(t)$.

Then, there is a $t_{0}$ which makes $h^{\prime}(t)=0$ since $h(t)$ is a "bathtub" type function in $t$.

Further, $h(t)$ is decreasing within $\left(0, t_{0}\right)$ and increasing within $\left[t_{0},+\infty\right)$.

$\varepsilon(W)$ is decreasing if $h(t)$ is decreasing with $t$, then,

$$
\lim _{W \rightarrow 0} \phi(W)=2 \bar{F}_{q}(W) \bar{F}_{q}(2 W)(h(2 W)-h(W))<0
$$

Similarly, $\varepsilon(\mathrm{W})$ is increasing if $\mathrm{h}(\mathrm{t})$ is increasing with $\mathrm{t}$. Then,

$$
\lim _{W \rightarrow+\infty} \phi(W)=+\infty
$$

Thus, $\phi(W)$ is also a "bathtub" type function with $W$, and $\lim _{W \rightarrow 0} \phi(W)<0$. Then, $\varphi(0)<C_{r}<\varphi(+\infty)$.

Therefore, the solution of $w_{P}>0$ to Eq.(11) is existent and unique.

\section{References}

1. Castro I. T. and E. L. Sanjuan. An optimal maintenance policy for repairable systems with delayed repairs. Operations Research Letters 2008; 36(5): 561-564, http://dx.doi.org/10.1016/j.orl.2008.05.007.

2. Chang C. C. Optimum preventive maintenance policies for systems subject to random working times, replacement, and minimal repair. Computers \& Industrial Engineering 2014; 67: 185-194, http://dx.doi.org/10.1016/j.cie.2013.11.011.

3. GAO W., et al. Optimal Combinatorial Replacement Policy under a Given Maintenance Interval for the Combined Governor in Diesel Locomotives. Eksploatacja i Niezawodnosc - Maintenance and Reliability 2013; 15(2): 89-98.

4. KODO I. and N. TOSHIO. Optimal operation censoring policy of aircraft. 2012 Asia-Pacific International Symposium on Advanced Reliability and Maintenance Modeling. 2012. 184-191. 
5. Mingchih C. Optimal random replacement models with continuously processing jobs. Applied Stochastic Models in Business and Industry 2013; 29: 118-126, http://dx.doi.org/10.1002/asmb.952.

6. Nakagawa T. Maintenance theory of reliability. London: Springer, 2005.

7. NAKAGAWA T. PERIODIC AND SEQUENTIAL PREVENTIVE MAINTENANCE POLICIES. Journal of Applied Probability 1986; 23(2): 536-542, http://dx.doi.org/10.2307/3214197.

8. Nakagawa T., et al. A summary of periodic and random inspection policies. Reliability Engineering \& System Safety 2010; 95(8): 906-911, http://dx.doi.org/10.1016/j.ress.2010.03.012.

9. Sarkar A., et al. Survey of maintenance policies for the Last 50 Years. International Journal of Software Engineering \& Applications (IJSEA) 2011; 12(3): 130-148, http://dx.doi.org/10.5121/ijsea.2011.2310.

10. Sheu S.-H. and C.-C. Chang. An Extended Periodic Imperfect Preventive Maintenance Model With Age-Dependent Failure Type. IEEE TRANSACTIONS ON RELIABILITY 2009; 58(2): 397-405, http://dx.doi.org/10.1109/TR.2009.2020103.

11. SHEU S.-H., et al. An Extended Sequential Imperfect Preventive Maintenance Model with Improvement Factors. Communications in Statistics-Theory and Methods 2012; 41(7): 1269-1283, http://dx.doi.org/10.1080/03610926.2010.542852.

12. Sheu S.-H. and J.-P. Jhang. A generalized group maintenance policy. European Journal of Operational Research 1996; 96: 232-247, http:// dx.doi.org/10.1016/S0377-2217(96)00073-2.

13. Sheu S.-H., et al. Extended optimal replacement model with random minimal repair costs. European Journal of Operational Research 1995; 85: 636-649, http://dx.doi.org/10.1016/0377-2217(93)E0364-4.

14. Wu S. Preventive Maintenance Models:A Review. London: Springer, 2011.

15. Xu S., et al., Random fuzzy age-dependent replacement policy, in Fuzzy Systems and Knowledge Discovery, Pt 1, Proceedings, L. Wang and Y. Jin, Editors. 2005. 336-339.

16. Zhang Z., et al. Reliability Modeling and Maintenance Optimization of the Diesel System in Locomotives. Eksploatacja i Niezawodnosc Maintenance and Reliability 2012; 14(4): 302-311.

\author{
Wenke GAO \\ School of Energy and Power Engineering \\ Lanzhou University of Technology \\ Lanzhou 730050, China \\ School of Mechanical Engineering \\ Southeast University \\ Nanjing 211189, China
}

\section{Zhisheng ZHANG}

School of Mechanical Engineering

Southeast University

Nanjing, China, 211189

\section{Hong JI}

School of Energy and Power Engineering

Lanzhou University of Technology

Lanzhou 730050, China

\section{Yifan ZHOU}

School of Mechanical Engineering

Southeast University

Nanjing, China, 211189

\section{Qi LIU}

School of Mechanical Science and Engineering

Jilin University

Changchun, China, 130025

E-mail:gaowk_best@163.com 